\title{
A ABORDAGEM EDUCOMUNICATIVA EM PRÁTICAS PEDAGÓGICAS NA EDUCAÇÃO PROFISSIONAL DE JOVENS MARAJOARAS
}

\section{Hericley Serejo Santos ${ }^{1}$}

Ana Maria Leite Lobato ${ }^{2}$

Recebido em: fevereiro/2020

Publicado em: abril/2020

\section{RESUMO}

O presente artigo tem o objetivo de compreender como a abordagem educomunicativa está presente nas práticas pedagógicas aplicadas no Curso Técnico em Informática integrado ao Ensino Médio, do Instituto Federal do Pará (IFPA), Campus Breves, e como colabora para a formação de cidadãos emancipados e conscientes do direito à expressão e comunicação. Para isso, realizamos entrevistas semiestruturadas com oito professores no intuito de identificar a tipologia de linguagens, a metodologia aplicada, os resultados obtidos e o conhecimento sobre Educomunicação. A abordagem educomunicativa está presente nas práticas pedagógicas desses professores e, apesar da maioria desconhecer o termo, compreendem a importância de se promover a interface entre Educomunicação e Educação Profissional Tecnológica.

Palavras-chave: Educomunicação; Linguagens Midiáticas; Trabalho.

\footnotetext{
${ }^{1}$ Instituto Federal de Educação Ciência e Tecnologia do Pará, campus Belém. E-mail: hericleyrp@ gmail.com

${ }^{2}$ Instituto Federal de Educação Ciência e Tecnologia do Pará, campus Belém. E-mail: leao.jr@uol.com.br
} 


\section{ABSTRACT}

This article aims to understand how the educommunicative approach is present in the pedagogical practices applied in the Technical Course in Informatics integrated to the High School, of the Federal Institute of Pará (IFPA), Campus Breves, and how it collaborates for the formation of emancipated citizens and aware of the right to expression and communication. For this, we conducted semi-structured interviews with eight teachers in order to identify the typology of languages, the applied methodology, the results obtained and the knowledge about Educommunication. The educommunicative approach is present in the pedagogical practices of these teachers and, although most of them do not know the term, they understand the importance of promoting the interface between Educommunication and Technological Professional Education.

Key words: Educommunication; Media Languages; Job.

\section{INTRODUÇÃO}

$\mathrm{O}$ presente artigo tem o objetivo de compreender como a abordagem educomunicativa está presente nas práticas pedagógicas aplicadas no Curso Técnico em Informática integrado ao Ensino Médio, do Instituto Federal do Pará (IFPA), Campus Breves, e a forma como essa abordagem colabora para a formação de cidadãos emancipados e conscientes do direito à expressão e comunicação. Os dados aqui discutidos são resultados parciais da pesquisa exploratória do projeto de pesquisa intitulado "O ensino e apropriação de linguagens midiáticas na educação profissional de jovens marajoaras", do Programa de Pós-Graduação em Educação Profissional e Tecnológica (ProfEPT), que tem o objetivo geral de desvelar as contradições e mediações, presentes entre o processo de ensino e apropriação de linguagens midiáticas e os alunos do Curso Técnico em Informática integrado ao Ensino Médio do IFPA Campus Breves, e suas contribuições para uma formação profissional e emancipatória desses sujeitos. 
O desenvolvimento das tecnologias de informação e comunicação (TIC) proporcionou aos indivíduos um acesso cada vez mais rápido às informações. No entanto, dada a quantidade e a velocidade com que se sobrepõem, torna-se um desafio aos usuários refletir sobre os conteúdos recebidos e a veracidade do que é apresentado. Somado à baixa capacidade interpretativa e crítica oriunda da deficiência educacional, grande parte do discurso da mídia e do capital é assimilado pela população. É nesse contexto em que a Educomunicação, enquanto interface entre a Educação e a Comunicação, surge como uma maneira não só de promover a leitura crítica, mas de proporcionar o desenvolvimento de capacidades comunicativas que potencialize o exercício da cidadania, seja na recepção ou na expressão de ideias por meio de diferentes linguagens midiáticas ${ }^{3}$ (SOARES, 2011). A discussão sobre a apropriação dessas linguagens recebeu maior visibilidade na América Latina a partir dos estudos de Jesús Martín-Barbero (1997), que propôs a ruptura do paradigma de recepção dos meios de comunicação de massa, defendendo que os usuários não acolhem passivamente os conteúdos veiculados, mas promovem um jogo de ressignificação dos sentidos a partir das mediações culturais em que estão imersos.

Apesar de estar claramente exposto o impacto dos meios de comunicação na formação do cidadão, ainda são identificadas poucas iniciativas na Educação Profissional e Tecnológica que busquem desenvolver a dimensão de comunicação do discente, pelo menos entre a produção científica. Em um levantamento de artigos científicos que relacionam Educação Profissional e Tecnológica e Comunicação, realizado em dezembro de 2018, publicados nos últimos cinco anos (2013-2018) no Portal de Periódicos da CAPES, identificamos que apenas um trabalho apresentou a perspectiva educomunicativa (SANTOS-SEREJO; LOBATO, 2019).

Diante disso, neste trabalho, nos propomos a: a) discutir o papel da interface entre a Educação Profissional e Tecnológica e a Educomunicação no desenvolvimento e formação de cidadãos emancipados; b) identificar junto aos docentes a tipologia, a

\footnotetext{
${ }^{3}$ O significado completo da expressão linguagem midiática ainda não foi identificado na literatura. Autores, como Soares (2011), Orozco (2014) e Martín-Barbero (1997) não explicitam um sentido exato. No entanto, com a intersecção entre os dois temos que a compõe, compreendemos como o conjunto de signos e significados que integram e diferenciam cada tipo de mídia, enquanto canal de veiculação de informação e/ou interação de sujeitos. Vale ressaltar que a pesquisa está em andamento e a definição ou a construção de um significado da expressão estará presente na pesquisa final.
} 
metodologia e os resultados de práticas pedagógicas desenvolvidas sob uma abordagem educomunicativa e aplicadas no Curso Técnico em Informática integrado ao Ensino Médio do IFPA Campus Breves; e c) analisar as aproximações teóricas e metodológicas presentes nas práticas pedagógicas que desvelarem alguma característica da perspectiva educomunicativa, considerando a formação de cidadão emancipados e conscientes do direito à expressão e comunicação. Os esforços são ainda para verificar o quanto é legítima a necessidade que o produto da pesquisa final pretende atender, que consistirá no desenvolvimento de um processo de ensino e apropriação de linguagens midiáticas, o qual se materializará por meio de um curso online a ser publicado na Plataforma Massive Open Online Courses (MOOC) do IFPA ${ }^{4}$, visando estimular a apropriação dessas linguagens para a expressão e argumentação de ideias e o exercício da cidadania.

\section{A INTERFACE ENTRE A EDUCAÇÃO PROFISSIONAL E}

\section{TECNOLÓGICA E A EDUCOMUNICAÇÃO}

A interface entre a Educação e a Comunicação se articula através da uma relação dialógica e interdependente, onde as partes não apenas coexistem, mas estão contidas uma na outra; deste modo, “a educação só é possível enquanto 'ação comunicativa' (...) [e] toda comunicação - enquanto produção simbólica e intercâmbio /transmissão de sentidos - é, em si, uma 'ação educativa'" (SOARES, 2011, p. 17). Assim, a Educomunicação é compreendida como um campo epistemológico que, para além dos processos de ensino e aprendizagem, tem o desafio de romper limites com os processos meramente instrutivos e expandir seu alcance a quase todos os âmbitos da vida (OROZCO, 2014). Conceitualmente, compreendemos esse campo como "o conjunto das ações voltadas ao planejamento e implementação de práticas destinadas a criar e desenvolver ecossistemas comunicativos abertos e criativos em espaços educativos" (SOARES, 2013 apud SOARES, 2011, p. 36).

\footnotetext{
${ }^{4}$ A Plataforma de Curso Online Aberto e Massivo (MOOC) do IFPA, criada em parceria com o Instituto TIM, é um Ambiente Virtual de Aprendizagem (AVA) que oferece cursos livres e gratuitos a qualquer usuário que tenha interesse às temáticas abordadas, a maioria na área de tecnologia da informação, combinando vídeos online com testes, simuladores e fóruns. Para ter acesso, o interessado deve realizar um cadastro e concluir as unidades para obter o certificado digital. Até o momento do desenvolvimento desta pesquisa, o ambiente contava apenas com material desenvolvido pela plataforma de origem, não ofertando conteúdos produzidos pelo Instituto Federal do Pará (IFPA, 2020).
} 
Tais ecossistemas dizem respeito aos diferentes ambientes sociais onde as pessoas se relacionam (família, escola, centros culturais, espaços virtuais) e sua construção no ambiente escolar requer esforços baseados em uma clareza conceitual, planejamento, acompanhamento e avaliação. Para isso, Soares (2011) aponta a pedagogia de projetos como uma abordagem capaz de proporcionar dialogicidade no processo pedagógico de construção do conhecimento entre os sujeitos. De acordo com Koffermann (2018), os projetos educomunicativos devem considerar quatro critérios essenciais: a participação ativa de todos os sujeitos envolvidos; a finalidade educativa, com a clareza da metodologia e dos objetivos entre os sujeitos sociais; a continuidade no processo de desenvolvimento da prática, que diz respeito ao amadurecimento, acompanhamento, reflexão crítica e a capacidade de enfrentar imprevistos; e a repercussão social para a comunidade dos resultados obtidos.

Utilizar projetos como metodologia de ensino consiste em uma estratégia já adotada pelos Instituto Federais, onde se busca "contribuir para a construção da autonomia intelectual dos alunos, por meio da pesquisa, assim como formar atitudes de cidadania, de solidariedade e de responsabilidade social" (MOURA, 2007, p. 24). Esse protagonismo e a autonomia no pensar e no fazer, promovidos pela Educomunicação, são igualmente compartilhados pelo projeto societário de Educação Profissional e Tecnológica ao qual nos filiamos, dedicado a uma formação omnilateral que integra as dimensões trabalho, ciência e cultura em uma relação indissociável, dando forma à concepção do trabalho como princípio educativo (RAMOS, 2007).

A comunicação também é considerada como uma das dimensões que precisa ser desenvolvida no sujeito em formação, na qual se busca ensinar o discente a se comunicar, de forma que ele aprenda a interagir com a natureza e com os demais indivíduos para construir sua existência por meio do trabalho (NOSELLA, 2007). No entanto, da mesma forma como a Educomunicação despende esforços teóricos e metodológicos para não se limitar aos aspectos utilitaristas das mídias e suas tecnologias, a Educação Profissional constrói sua proposta pautada em uma concepção ontológica do trabalho que não o restringe à ação humana sobre a natureza simplesmente como uma intervenção para atender a necessidade da existência, mas 
como um processo de criação de pressupostos para alcançar a liberdade (NETTO, 2006, p. 188 apud FRIGOTTO, 2009, p. 180).

Percebemos que a Educação Profissional Tecnológica e a Educomunicação, como campos de pesquisa distintos que convergem essencialmente em seus objetos e ambientes de atuação, apresentam o projeto ético-político-pedagógico como um dos principais elementos de interface. Assim como a primeira posiciona-se como uma proposta para fortalecer a formação de cidadãos emancipados e conscientes do papel transformador que podem assumir na sociedade (ARAUJO; FRIGOTTO, 2015), a segunda pretende proporcionar, a partir da compreensão crítica da realidade social e da apropriação de linguagens midiáticas, condições para despertar nos jovens o interesse de construir uma sociedade mais justa por meio da capacidade de comunicar (SOARES, 2011). Dessa forma, a apropriação das linguagens midiáticas, a partir dessa interface, converte-se então em uma significativa estratégia de emancipação dos sujeitos, em uma prática social.

\section{PERCURSO METODOLÓGICO}

De caráter qualitativo, os dados que apresentamos são parte de uma pesquisa exploratória e foram obtidos por meio de entrevistas semiestruturadas com oito professores do curso Técnico em Informática Integrado ao Ensino Médio do IFPA Campus Breves ${ }^{5}$, localizado no Município de Breves, ao norte do Estado do Pará, na mesorregião do Marajó, arquipélago fluviomarinho considerado o maior do planeta (ALVES, 2016). Para Chisté (2016), na pesquisa-ação, essa fase corresponde aos primeiros contatos com os sujeitos e com a problemática. Como a pesquisa principal será realizada junto aos estudantes do $2^{\circ}$ Ano, selecionamos docentes que ministram aulas no respectivo período, considerando as ponderações de Gaskell (2002), para o

\footnotetext{
${ }^{5}$ O IFPA Campus Breves foi criado pela Portaria n 1366 de 08 de dezembro de 2010 e abrange, além da sede, outros oito municípios localizados na mesorregião, a saber: Afuá, Anajás, Chaves, Bagre, Curralinho, Gurupá, Melgaço e Portel. O Campus foi criado alinhado ao Plano de Desenvolvimento do Marajó em um período de transição do modo de geração de renda, até então mantida por atividades de extração da madeira, com a missão de ofertar formação profissional que potencializasse os Arranjos Produtivos Locais e desse condições à população de despertar a outros modos de geração de renda para contribuir ao desenvolvimento sustentável da região (IFPA, 2019).
} 
qual a intenção na pesquisa qualitativa é explorar as opiniões e os diferentes posicionamentos sobre um determinado assunto, e não os quantificar. Outro critério adotado foi escolher quatro disciplinas da Base Comum e quatro da Base Tecnológica, considerando o nível maior ou menor de afinidade que teriam em relação ao uso de linguagens midiáticas. Em aspectos gerais, entrevistamos $40 \%$ dos docentes do colegiado do curso.

O roteiro da entrevista foi composto por quatro perguntas, cada uma se caracterizando como um eixo analítico relacionado ao objeto de estudo, onde buscamos: 1) Identificar a tipologia de linguagens midiáticas adotadas nas práticas pedagógicas; 2) a metodologia de aplicação dessas linguagens em sala de aula; 3) os resultados ou efeitos observados pelos docentes após a aplicação, sejam imediatos ou não; 4) e se os professores conheciam algo sobre Educomunicação ou tinham alguma percepção sobre a interface entre Educação e Comunicação. Conforme propõe Gaskell (2002) e Oliveira (2010), identificamos na transcrição das entrevistas dados relevantes que foram estruturados em uma matriz, onde as linhas continham a identificação codificada dos docentes e as colunas, a distribuição das falas e, das categorias empíricas, de maneira que os dados foram analisados e interpretados de acordo com os referidos autores. Para preservar a identidade dos participantes, elaboramos uma codificação formada por quatro dígitos: $\mathrm{E}$ - entrevistado; (n) - referente à ordem de realização da entrevista (1= primeiro, 2= segundo, e sucessivamente); BC (Base Comum) ou BT (Base Tecnológica) - relacionado ao grupo de disciplinas do qual o entrevistado participava.

As aproximações teóricas e metodológicas das práticas pedagógicas à perspectiva educomunicativa foram explanadas e abordadas sob a luz das bases conceituais da Educação Profissional e Tecnológica e dos princípios que fundamentam as práticas educativas no campo da Educomunicação.

\section{A SUTIL E EVIDENTE PRESENÇA DA ABORDAGEM} EDUCOMUNICATIVA 
As entrevistas demonstraram que as linguagens midiáticas são utilizadas nas práticas pedagógicas dos referidos professores. Apesar de não haver plena consciência sobre a apropriação dessas linguagens para a formação cidadã e usufruto do direito à comunicação e expressão, as práticas relatadas apresentam uma abordagem educomunicativa, mesmo que em caráter inicial, ao desenvolverem capacidades comunicativas que poderão contribuir a essa finalidade social. Entre os docentes, apenas dois $(25 \%)$ já tinham ouvido falar sobre o termo Educomunicação, mas de forma superficial; os 75\% (seis) restantes o desconheciam, no entanto, apresentaram clareza sobre a adoção de elementos ou estratégias do campo da Comunicação nas metodologias desenvolvidas dentro e fora de sala de aula, principalmente àqueles relacionados às tecnologias da informação.

Observamos que as linguagens midiáticas são abordadas de duas formas nas práticas pedagógicas desses docentes. Na primeira, são usadas como instrumento ou recurso (ou materialidade destinada à análise de determinado conteúdo) em aulas expositivas, por meio do uso de fotografias, artigos de blogs, filmes e outras linguagens para facilitar o processo de aprendizagem e compreensão do conteúdo ensinado. $\mathrm{Na}$ segunda, as linguagens midiáticas aparecem como mediação por meio da qual os discentes demonstram o nível de compreensão que alcançaram sobre determinado conteúdo, o que se aproxima da apropriação proposta pela Educomunicação.

Cada eixo analítico apresentou uma lista de categorias empíricas que foram agrupadas para compor a análise das entrevistas. No eixo tipologia, realizamos um agrupamento dos recursos ou elementos de comunicação citados para destacar cinco tipos de linguagens que são promovidas nas práticas pedagógicas pelos docentes: a linguagem textual, onde se encontram meios de comunicação como portal ou site de notícias, revista e blogs, geralmente com conteúdos jornalísticos; linguagem fotográfica, representada por imagens estáticas ou dinâmicas (formato $\mathrm{GIF}^{6}$ ); linguagem audiovisual, que conta com mídias que veiculam predominantemente vídeos, como ocorre no cinema ou no Youtube; linguagem publicitária, composta por materiais de

\footnotetext{
${ }^{6}$ Graphics Interchange Format (GIF) é um formato de imagem que permite animações. No caso dos professores, são geralmente aplicadas em apresentações em PowerPoint para sinalizar um movimento físico ou atrair a atenção dos estudantes.
} 
comunicação visual que expõem textos e imagens voltados à promoção de produtos ou conceitos comerciais; e linguagem multimídia, onde estão aqueles canais mais híbridos, de difícil definição dos elementos predominantes, como ocorre com o Facebook e outros aplicativos que veiculam texto, som e imagem quase na mesma proporção. Confira no gráfico 1 a distribuição dos tipos de linguagens.

Gráfico 1: Tipos de Linguagens Midiáticas citadas pelos entrevistados

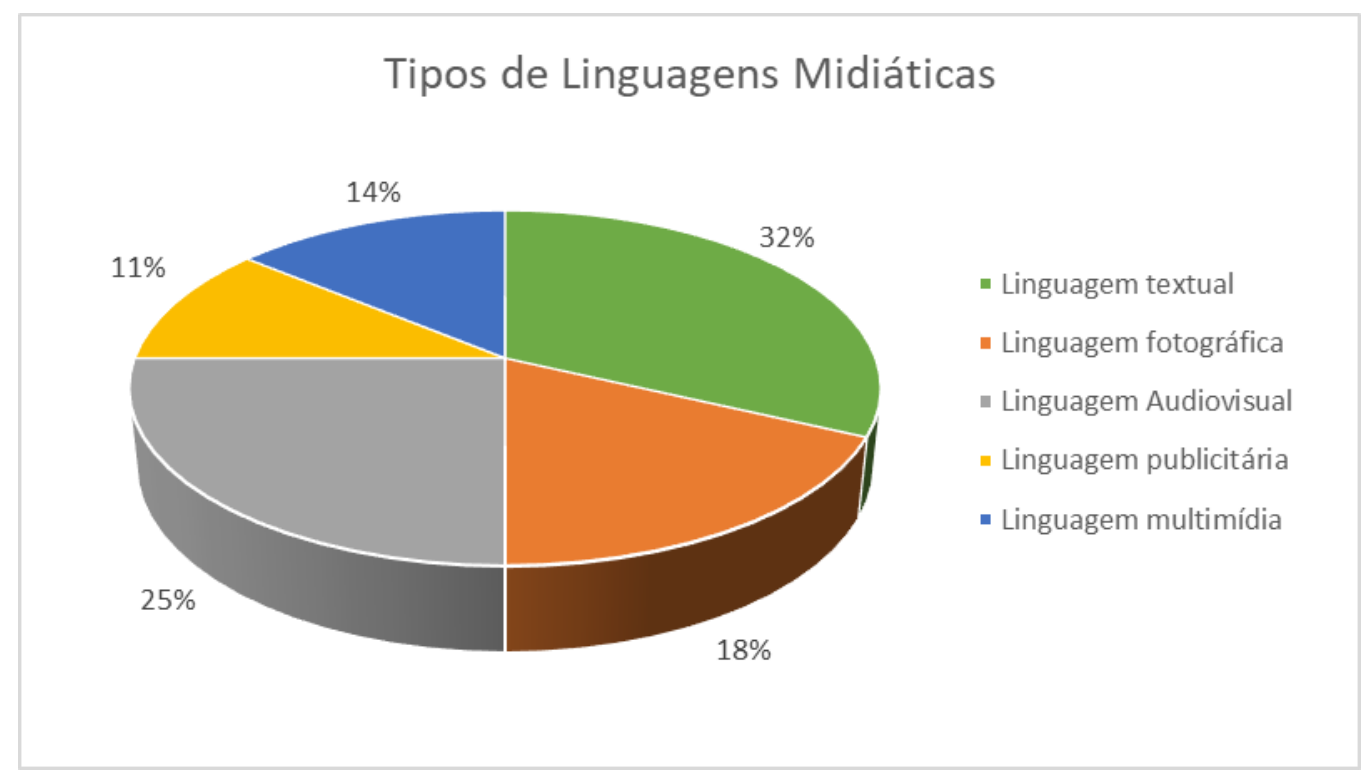

Fonte: Elaborado pelos autores

Apesar do gráfico evidenciar o maior uso de mídias que apresentam a predominância da linguagem textual, percebemos que uma parte dos professores buscam evitar o uso demasiado do texto escrito e a outra compreende que deveria melhorar suas práticas a partir da diversificação na forma de apresentá-lo aos discentes, usando recursos, como por exemplo, histórias em quadrinhos, que podem contribuir igualmente para o entendimento de conceitos das disciplinas. Um dos entrevistados aponta para o que poderia ser o motivo disso: "Meu objetivo na verdade é resumir ao máximo o conteúdo para que eu consiga ministrar ele como um todo, embora eu saiba que utilizar esses recursos como uma literatura diferenciada ajuda muito no processo de envolvimento do aluno com a aula" (E3BC). 
Observamos que as linguagens midiáticas são selecionadas conforme dois critérios: a afinidade e a adequação ao conteúdo; ou seja, são pautadas, na maioria das vezes, pela experiência do próprio professor. Notamos também que os discentes costumam apresentar três papéis principais: a recepção, referente à exposição do conteúdo pelo docente e a reflexão que os materiais midiáticos proporcionam; a interação entre discentes e docentes, que emerge do processo de leitura crítica do material apresentado; e a apropriação, quando o estudante exercita algum conhecimento por meio de alguma linguagem midiática. Esses papéis, entretanto, não são atribuídos de forma consciente pelos professores.

No eixo metodologia, apareceram categorias como leitura crítica, aprendizagem significativa, mundo do trabalho, apropriação, projeto integrado, recurso didático e inovação. No geral, percebemos que recorrer às linguagens midiáticas configura-se em uma estratégia para manter a atenção do aluno em conteúdos teóricos e proporcionar uma diversidade e dinamismo na didática aplicada pelo professor.

Diante da facilidade de acesso à informação, identificamos um cuidado especial dos docentes na seleção das fontes de onde os conteúdos são extraídos com o intuito de garantir a fidedignidade das mensagens em relação às teorias científicas dos campos de conhecimento e uma leitura crítica alinhada à realidade. Foi interessante observar que, enquanto a maioria dos docentes buscam desenvolver a leitura crítica a partir das mensagens produzidas pelas mídias, um dos professores realiza um movimento diferente, levando os estudantes a se desapegarem de suas preconcepções e evitarem julgamento de valor no primeiro contato com um produto da linguagem textual com o intuito de levá-los a uma interpretação mais profunda, onde sejam capazes de escutar o autor, para somente após isso adotarem uma postura diante da mensagem.

A maior parte dos docentes demonstrou que promove o ensino dos temas e assuntos presentes no currículo do curso baseado em uma aprendizagem significativa, aquela em que um novo conhecimento apresenta relação com informações ou 
aspectos relevantes da estrutura cognitiva do sujeito (MOREIRA, 2017). Essa perspectiva perpassa também pela escolha dos recursos tecnológicos utilizados nas atividades pedagógicas. Pelas características do curso, poderíamos partir da premissa de que, pelo menos a maioria, teria certa facilidade ou afinidade em utilizar o computador. Mas não é com isso que os professores se deparam. A facilidade de acesso ao celular condiciona, em grande parte, as atividades que são propostas pelos docentes, uma forma de não os distanciar dos recursos e técnicas fundamentais para a formação deles. Neste sentido, o professor E5BT diz o seguinte:

Quando a gente vai partir de uma prática para uma coisa que a gente quer que eles façam, a gente sempre tenta relacionar aquilo com alguma coisa que eles consigam fazer no celular, porque eles conseguem fazer. (...) O que a gente tem encontrado é que na área de informática eles são extremamente deficientes, se não envolver a parte de celular. (...) Se tu não der opção pra eles fazerem no celular, eles preferem fazer escrito à mão do que digitar (E5BT).

Os professores demonstraram também constante preocupação de projetar as práticas pedagógicas para o mundo do trabalho, evidenciando o quanto o saber teórico e técnico pode contribuir diretamente para a futura atuação profissional dos discentes. Essa relação é utilizada ainda como uma forma de conquistar o comprometimento e a dedicação dos discentes. Por outro lado, os docentes sensibilizam os estudantes a compartilharem e aplicarem o conhecimento junto a grupos sociais como a família, de forma a ajudar outras pessoas em ambientes diversos; uma perspectiva que enfatiza o papel cidadão dos discentes.

Por mais que não haja ainda o entendimento profundo sobre a Educomunicação e as possibilidades que ela apresenta para o processo de ensino e aprendizagem, observamos que há práticas pedagógicas que destacam o protagonismo dos estudantes na aplicação de alguma linguagem midiática:

A gente já fez exercícios que eles gostaram, tipo, deles gravando tutoriais. Faz o seguinte: eu quero que tu faças um programa para mim assim, assim, assim, mas eu não quero o programa, eu quero que tu graves um vídeo ensinando outra pessoa a fazer o programa. 
Precisa ter os dois: a tela do computador e eles. Aí eles pegam, eles gravam ensinando o que tem que fazer (E5BT).

Ao proporem a elaboração de mensagens destinadas para diferentes tipos de mídias, em especial, aquelas caracterizadas como mídias sociais (WhatsApp, Facebook e Youtube), os docentes demonstraram esforços em desenvolver certa autonomia nos estudantes, deixando que eles próprios escolhessem a linguagem midiática mais adequada ao formato da mensagem produzida. Essa maneira de conduzir a prática pedagógica pode contribuir para que esses discentes apresentem maior desenvoltura ao produzir e veicular conteúdos de interesse pessoal ou coletivo. E conforme são desafiados, os discentes se apropriam das linguagens, mesmo sem haver uma intenção consciente dos seus professores em aspectos teóricos ou epistemológicos. O caminho que levou os docentes a adotarem essa perspectiva educomunicativa está muito relacionado à sensibilidade que eles apresentaram em seus relatos de adequar a metodologia de ensino à realidade dos alunos, buscando aproveitar o conhecimento que eles já têm sobre uso do celular e de aplicativos de mídias sociais e associá-lo ao conteúdo técnico que precisam aprender.

As práticas educomunicativas geralmente são desenvolvidas no formato de projetos colaborativos. Os projetos integradores apresentam características semelhantes nos Institutos Federais (MOURA, 2007). No entanto, conforme relatou um dos docentes, essa metodologia apresenta certos problemas por desconsiderar o fato de que ela se soma às 18 disciplinas que os estudantes já devem realizar, sobrecarregando-os de atividades.

Conteúdos de linguagem audiovisual transformam-se em objeto de análise diante de um tema. Um dos professores, por exemplo, utiliza vídeos do Youtube em formato tutorial ou explicativos e propõe aos alunos que verifiquem, tendo como suporte livros e artigos científicos, se realmente tudo o que o usuário explica no vídeo está correto ou não. Uma forma que ele encontrou, inclusive, de sensibilizá-los a respeito das notícias falsas (fake news) e da necessidade de sempre verificarem a veracidade das informações recebidas por diversos canais de comunicação. As 
linguagens midiáticas também se apresentaram como um meio propício para o docente desenvolver a criatividade e inovação. Um dos professores apresentou uma metodologia que nos pareceu bem peculiar, o que ele chamou de fichamento de vídeo. Ao utilizar videoaulas retiradas do Youtube para o aprofundamento de temas abordados em sala, ele propõe que os estudantes realizem a transcrição do conteúdo como uma forma de reforçar o aprendizado e a memorização das fórmulas e esquemas.

No eixo resultados, destacamos categorias empíricas como apropriação, sensibilidade (relacionada à aprendizagem significativa), comprometimento e autonomia. De acordo com um dos docentes, a realização de atividades pedagógicas que exigem uma aplicação mais prática do conteúdo por meio de alguma linguagem midiática gera maior comprometimento dos discentes em sua execução, o que ele busca intensificar por meio da elaboração de trabalhos interdisciplinares. Além da assimilação e aprendizagem do conteúdo, o uso dessas linguagens também contribui para o estudante desenvolver a autonomia que necessitará no mundo do trabalho, conforme inferimos a partir do enunciado do entrevistado E8BC.

Eu percebi que o que melhora na aula, assim, de imediato, é uma assimilação do conteúdo em si. (...) Eu estou dizendo assim para eles adquirirem essa habilidade deles assistirem vídeoaula, e procurarem conhecimento, claro, sempre ter o cuidado de fonte confiáveis. (...). Essa é a palavra, desenvolver essa autonomia (E8BC).

No eixo interface, identificamos predominantemente as categorias comunicação, recurso didático e aspectos negativos. A relação entre Educação e Comunicação é compreendida como algo evidente, uma necessidade alinhada a demandas não somente referentes à realidade dos discentes, mas da própria instituição de ensino. O processo comunicativo é percebido em diferentes direções, envolvendo diferentes sujeitos por meio de linguagens midiáticas diversas, mas em especial, pelas mídias alternativas, que permitem uma abrangência às vezes inimaginável, como descreveu um dos entrevistados: 
A questão de trazer a comunicação para dentro da sala de aula, para educação, é (...) uma coisa que hoje em dia está intrínseco. (...) Eu acho que a comunicação tem que tá trazendo sempre pra dentro da nossa sala de aula e até paro nosso trabalho sair dos muros da escola, (...) até porque o Youtube, seja lá no Face, tem uma abrangência que às vezes a gente nem imagina (E6BT).

No entanto, alguns professores assumiram que, junto às linguagens midiáticas, há aspectos negativos que precisam ser considerados e expostos aos alunos para que eles consigam compreender os contextos adequados para utilizá-las, tendo condições de se apropriar mais e saber aplicá-las para melhor expressar suas ideias e opiniões.

\section{CONSIDERAÇÕES FINAIS}

A partir dos relatos dos professores, compreendemos que a abordagem educomunicativa está presente nas práticas pedagógicas aplicadas no curso Técnico em Informática integrado ao Ensino Médio do IFPA Campus Breves. Existe uma compreensão significativa sobre a importância de se promover a interface entre Comunicação e Educação nas atividades realizadas em sala de aula, em específico, na Educação Profissional e Tecnológica, mesmo que nem sempre haja uma intenção consciente por parte do docente. O uso de linguagens midiáticas nas práticas pedagógicas representa uma busca do professor em inovar em sua metodologia, apesar de esbarrar em obstáculos de infraestrutura, como a indisponibilidade de acesso à internet para os estudantes.

O maior foco dos professores ainda permanece nos aspectos instrumentais dos recursos de comunicação. A apropriação das linguagens para o exercício da cidadania encontra-se em um plano mais profundo da abordagem educomunicativa empregada, e não tivemos como verificar se os estudantes a alcançam de fato, nem se os docentes alimentam essa intenção em algum momento do desenvolvimento da prática pedagógica. 
Diante disso, compreendemos que o produto de nossa pesquisa final, o processo de ensino e apropriação de linguagens midiáticas materializado em um Curso Online a ser publicado na plataforma MOOC do IFPA, poderá contribuir para evidenciar aos professores e demais usuários como a interface entre a Educação Profissional e Tecnológica e a Educomunicação, bem como o entendimento sobre as mídias e a apropriação de suas linguagens, é capaz de colaborar com a formação de cidadãos conscientes e emancipados, dando condições para que usufruam do direito à expressão e comunicação e promovam as transformações necessárias em sua realidade social.

\section{REFERÊNCIAS}

ALVES, Fábio (Org.). A função socioambiental do patrimônio da União na Amazônia. Brasília: Ipea, 2016.

ARAUJO, Ronaldo; FRIGOTTO, Gaudêncio. Práticas pedagógicas e ensino integrado. Revista Educação em Questão, Natal, v. 52, n. 38, p. 61-80, mai/ago. 2015. Disponível em: https://periodicos.ufrn.br/educacaoemquestao/article/view/7956/5723. Acesso em: 28 jul. 2018.

CHISTÉ, Priscila de Souza. Pesquisa-Ação em mestrados profissionais: análise de pesquisas de um programa de pós-graduação em ensino de ciências e de matemática.

Ciência \& Educação, Bauru, v. 22, n. 3, p. 789-808, 2016. Disponível em: http://www.scielo.br/scielo.php?script=sci_arttext\&pid=S151673132016000300789\&l ng=pt\&tIng=pt. Acesso em: 27 fev. 2019.

FRIGOTTO, Gaudêncio. A polissemia da categoria trabalho e a batalha das ideias nas sociedades de classe. Revista Brasileira de Educação, Rio de Janeiro, v. 14, n. 40, p. 168-194, 2009. Disponível em: http://www.scielo.br/pdf/rbedu/v14n40/v14n40a14 .pdf. Acesso em: 27 out. 2018.

GASKELL, George. Entrevistas individuais e grupais. In: BAUER, Martin W; GASKELL, George (editores). Pesquisa qualitativa com texto, imagem e som: um manual prático. Petrópolis, RJ: Vozes, 2002. p. 64-89.

INSTITUTO FEDERAL DO PARÁ. Minuta do Plano de Desenvolvimento do Campus Breves (2019-2023). Disponível em:

http://breves.ifpa.edu.br/documentos/ascom/1582-pdc-breves-2019-2023-minutacompressed/file. Acesso em: 26 fev. 2020. 
INSTITUTO FEDERAL DO PARÁ. Plataforma MOOC: cursos livres, online e gratuitos. Belém, 2020. Disponível em: https://mooc.ifpa.edu.br/. Acesso em: 26 fev. 2020. KOFFERMANN, Marcia. Como sistematizar um Projeto Educomunicacional? 1a Ed. Brasília: Edebê Brasil, 2018, 16p.

MARTÍN-BARBERO, Jesús. Dos meios às mediações: comunicação, cultura e hegemonia. Rio de Janeiro: Editora UFRJ, 1997.

MOURA, Dante Henrique. Educação básica e educação profissional e tecnológica: dualidade histórica e perspectivas de integração. Holos, v. 2, n. 23, p. 4-30, 2007. Disponível em: http://www2.ifrn.edu.br/ojs/index.php/HOLOS/article/viewFile/11/110. Acesso em: 27 fev. 2019.

NOSELLA, Paolo. Trabalho e Perspectivas de formação dos trabalhadores: para além da formação politécnica. Revista Brasileira de Educação, Rio de Janeiro, v. 12, n. 34, p. 137-151, jan/abr. 2007. Disponível em: http://www.scielo.br/pdf/\%0D/rbedu/ v12n34/a11v 1234.pdf.Acesso em: 24 set. 2018.

OLIVEIRA, Marli André. Como fazer pesquisa qualitativa. Petrópolis: Rio de Janeiro: Vozes, 2010, p. 98.

OROZCO GÓMEZ, Guilherme. Educação: recepção midiática, aprendizagens e cidadania. São Paulo: Paulinas, 2014.

RAMOS, M. Concepção do ensino médio integrado. Seminário sobre Ensino Médio, Natal-RN, 2007. Disponível em: http://forumeja.org.br/go/sites/forumeja.org.br.go /files/concepcao_do_ensino_medio_integrado5.pdf. Acesso em: 30 out. 2018.

SANTOS-SEREJO, Hericley; LOBATO, Ana Maria Leite. A dimensão comunicacional do discente na produção científica em Educação Profissional e Tecnológica de 2013 a 2018. In: Congresso Brasileiro de Ciências da Comunicação - Intercom, 42, 2019, Belém, PA. Anais (on-line). Belém: Intercom, 2019. Disponível em: http://portalintercom.org.br/anais/nacional2019/resumos/R14-0359-1.pdf. Acesso em: 20 out. 2019.

SOARES, Ismar de Oliveira. Educomunicação: o conceito, o profissional, a aplicação: contribuições para a reforma do Ensino Médio. São Paulo: Paulinas, 2011. 